\title{
Sustainable Management of the Freshwater Resources of Greece
}

\author{
G.N. Zaimes" and D.Emmanouloudis \\ ${ }^{l}$ Kavala Institute of Technology, Dept. of Forestry and Management of the Natural Environment, Laboratory of Mountainous Waters \\ Management and Control, Drama Annex, 1st km Drama-Mikrohoriou, Drama, 66100, Greece,
}

Received 5 December 2011; Accepted 15 July 2012

\begin{abstract}
Despite living on the blue planet of our solar system with water covering more than the $70 \%$ of its extent, water quantities for humans but also the other living terrestrial organisms are not unlimited. Many countries face serious problems because of water shortage. Some of the reasons are: i) the largest quantities of water are either salty or frozen in the poles, ii) the rapid increase of the human population in the last centuries, iii) the unequal distribution of water on the planet, iv) the increased consumption of water by each person, v) the multiple uses of water and vi) the increased pollution of water. With the imminent impacts of climatic change, the pressure on freshwater resources will only increase. Greece is one of the countries that will also face problems with its freshwater resources because of its Mediterranean climate, the large quantities of water that its citizens consume compared to other countries and because an important percentage of Greece's terrestrial freshwater resources originate from neighboring countries. In order to ensure sustainable water resources for future generations management measures should be taken. Specifically all the citizens need to realize that the country's quantities of freshwater are limited. Simultaneously reliable and long-term data need to be collected throughout the country that will allow to calculate accurately the water budgets for the river basins of Greece. However it is also essential to estimate future water budgets based on population projections but also taking into consideration climate change impacts. Based on these water budgets sustainable management plans need to be developed for the basins of the country that should include innovative and environmentally-friendly ideas for their best exploitation, conservation and pollution reduction. One of the keys for these management plans to be successfully is the need to change the perceptions of its citizens and enhance the collaboration between the institutions and organization that are responsible and deal with this resource. In addition, in most developed countries of world, Universities are educating citizen-volunteers that afterwards create organizations for the protection of freshwater resources and to increase the awareness of their fellow-citizens. Universities and Technological Educational Institutions (TEI) in Greece could also develop and promote similar programs. Overall with the appropriate actions today, the freshwater resources can be ensured for future generations.
\end{abstract}

Keywords: Freshwater resources, sustainable management, Greece.

\section{Introduction}

Water is considered by many as the most precious natural resource in the world, even more important than gold and oil. Their argument is simple but very important; no person can live without water. The human organism can survive only few days without water, while for one and half month without food. Water is essential for the human body to function. The human body contains from $55 \%$ up to $78 \%$ water depending on the age and his weight. In order for the body to function properly 1 to 7 liters of water per day are required. The quantity that each person consumes everyday also depends on the weather conditions and the activities the person is doing e.g. if a person is running or training he/she will consume larger quantities of water than a person that is watching television. If the human body does not receive the appropriate quantities of water then the water budget of body

\footnotetext{
*E-mail address: zaimesgeorge@gmail.com

ISSN: 1791-2377 @ 2012 Kavala Institute of Technology. All rights reserved.
}

will become negative and the organism will suffer from dehydration. Dehydration is a very dangerous situation that can cause very serious health problems, and even death.

The United Nation (UN) has also recognized the importance of water. The United Nations Conference on Environment and Development (UNCED) in Rio de Janeiro, Brazil in 1992, proposed March $22^{\text {nd }}$ of each year as the international observance of the World Water Day (see http://www.worldwaterday.org/). Since 1993, this day is devoted every year to implement UN recommendations and promotes concrete activities regarding the world's water resources.

Observing our planet from space will create the impression that it has the capacity to support an unlimited number of organisms that depend on water for their survival. This impression is created because our planet from space appears blue since water covers more than the $70 \%$ of the planet's surface. However reality is quite different because the largest quantities of water are not drinkable to humans and most of the other terrestrial organisms. The majority of 
the planet's water is seawater $(97.5 \%)$ with only a very small percentage as freshwater $(2.5 \%)$ [1]. Desalination is required in order for humans to use seawater. Desalination refers to the process that removes amounts of salt and other minerals from water. In other words desalination is a method to transform seawater, or brackish water into drinkable water. While many different processes have been developed, desalination continues to be very expensive and is applied mainly in rich countries with dry climate, poor in drinkable water and with easy access to salty water.

Even from the freshwaters supplies of our planet only a small percentage is easily exploitable and readily usable to humans. Specifically the largest percentage (68.7\%) of freshwater is in the two poles and in glaciers in the form of ice [1]. The water in this case is also not easily exploitable and readily available. The second largest percentage (30.1\%) is groundwater. In order to use this freshwater source pumps need to be used. The cost typically is smaller than the activities for desalination and for the exploitation of the ice of the glaciers or the poles. However the cost for pumping groundwater depends on the depth that it is found in (typically the deeper it is the more costly it is). In addition, there are cases where the quality of water of the aquifers is very poor and cannot be used either for human water supply or for irrigation. The most readily-available and easily exploitable freshwater supplies are surface waters but unfortunately their percentage is very small $(0.3 \%)$. Surface waters include lakes $(87 \%)$, rivers $(2 \%)$ or marshes $(11 \%)$. It must be noted that in many cases even their water can be salty or of very poor quality and not readily available without purification processes. The surface water and groundwater constitute the land freshwater resources, that overall are a very small percentage of the planet's water but constitute the main water source of most countries of the world. To better understand how small the easily exploitable and readily available this freshwater is, let's assume that all of the planet's water is 1000 milliliters then the groundwater would only be 3 milliliters and the surface waters only 2 drops [2].

\section{Worldwide Water Resource Issues}

\subsection{Unequal Water Distribution}

The drinkable water quantities of our planet that are readily available to each person are quite small. The inequality in the distribution of the water resources of our planet only extrapolates the issue of the limited freshwater resources quantities. Specifically, while there are regions that have an average annual rainfall greater than $11.500 \mathrm{~mm}$ (Waialeale Mountain, USA; considered the wettest place on the planet) there are also other regions with an average annual rainfall less than $1 \mathrm{~mm}$ (Arika, Chile) [3]. The quantity of rainfall that falls in a region also leads to very different ecosystems; earth has ecosystems from the tropical forests in the Amazon, Congo and South-eastern Asia to the deserts such as the Sahara, the Arabic and the Gobi in Central Asia. This indicates that in the world there are regions that face significant problems (e.g. floods, landslides) because of the excessive quantities of water they receive while other regions face the phenomenon of water shortage daily. Water shortage is the lack or the insufficiency of water for the basic needs of a region. Finally a large inequality also exists in the reserves of water of the various continents, regions and countries. Latin America has $31 \%$ of world reserves in drinkable water that is 12 times more water than what is available to Southern Asia [3]. Brazil and Canada are countries that have a surplus in their reserves of water while the countries in the Middle of East (Lebanon, Jordan, Israel etc.) cannot even cover the needs of their population [3]. In the Mediterranean region the northern region (European part) receives approximately $2 / 3(68 \%)$ of the natural freshwater resources, the eastern region (Asian part) approximately a quarter $(23 \%)$ and southern regions (North Africa) approximately a tenth (9\%) [4].

\subsection{Population Rapid Growth}

In the $20^{\text {th }}$ century the population of the earth has increased exponentially. The population growth is the result of the technological growth and advances that have led to significant advances in medicine that has help fight illnesses and diseases and increased life expectancy but also because food production has increased. The population of the earth is expected to reach or exceed 9 billion by $2050[5,6]$. However, the quantities of water of our planet have not increased or decreased substantially since its creation. This means that with the same quantities of water, earth needs to support a human population that continues to increase exponentially. The increase of population is a significantly more important problem for the third-world countries where it is has been stated that up to $80 \%$ of their population will not have direct access to drinkable water in the near future [6].

\subsection{Water Consumption}

The rate of population growth of the developed countries is significantly slower than those of the developing or thirdworld countries. Based on this fact someone could make the assumption that the developed countries will not face water shortage problems. However this is not true because of the daily personal consumption of water in the developed countries. Personal consumption is considered the quantities of water that someone uses in order to survive e.g. water for drinking, cooking, personal hygiene etc. The quantities of water humans consumed during the Middle Age were 10-15 liters per day, increased to 150 liters per day in the eighteenth century while today have reached the 330-500 liters per day [2]. The reason why a range is provided for today's consumption is because water consumption differs significantly from country to country particularly between developed and third-world countries. In any case it can be said that the personal requirements of today people for water have increased by more than 30 times compared to the requirements during the Middle Age, a very significant increase in water consumption.

\subsection{Multiple uses}

Water is not only used for personal individual needs. Water also has many other uses that can be conflicting with each other. These uses can be separated in three big categories: a) consumptive, b) disruptive and c) cooperative. Consumptive are those uses that return the water to the natural environment in a degraded quality compared to its quality prior to its use. Examples of consumptive uses are: a) irrigation for agriculture, b) water supply for municipalities, c) livestock farming, d) industry and e) aquaculture. Disruptive water uses are when the human activity mainly influences the natural flow of rivers of lakes. Examples are: 
a) transportation of goods with boats in rivers, b) creation of dams for water storage or hydroelectric energy. Finally, uses are considered cooperative when they have a very small usually insignificant impact on the water of the natural environment. Examples of cooperative uses are: a) ecotourism, b) hunting and c) fishing. In general there are a lot of different stakeholders interested in water resources with different and in many cases conflicting views on how water should be used making managing water resources extremely difficult. One of the main reasons is because many times it is not possible to provide the uses of all the interested stakeholders.

\subsection{Water Pollution}

Water pollution is one of the most serious threats and problems worldwide. It is the leading cause of deaths and illnesses worldwide. It is estimated that more from 14,000 people die daily because of water pollution. In the United States, it was estimated that $45 \%$ of surveyed river kilometers and $47 \%$ of surveyed lake acres, were polluted [7]. Pollution is caused primarily because of consumptive uses, such as urban, industrial and agricultural [8] that intensified after the ninetieth century. These consumptive uses have degraded water quality considerably in all continents of our planet. The most important types of pollutants are pathogenic (e.g. bacteria), chemical (e.g. toxins, fertilizers, herbicides) and other materials (e.g. sediment) as well as thermal.

To confront water pollution most countries have taken serious preventive measures. The United States have enacted the Clean Water Act since 1972. The purpose of the act is to eliminate releases of high amounts of toxic substances and other pollutants into the water thus ensuring that surface freshwaters meet standards necessary that depend on its use. The European Union has implemented the Water Framework Directive (2000/60/EU) for the management and protection of waters [7]. Based on this framework directive the Member-States of the EU need to standardize and monitor European waters for their hydrologic basins and afterwards develop holistic management plans for the protection of the surface waters.

\subsection{Transboundary Basins}

In the natural environment, water flows through the path with the greatest slope and least obstacles and resistance. As a result surficial terrestrial aquatic ecosystems, such as rivers and the lakes do not follow the borders of countries. A river or lake can belong to two, three, four and even more countries. Europe has the most transboundary basins of all continents. Disputes and conflicts among countries that share water resources have been quite frequent in the past but even today $[10,11]$. In many cases water has even caused wars. Despite the difficulties it is possible with proper communication and understanding among the sharing countries to also achieve collaborations [12]. More specifically in the last 50 years while 37 disagreements with some form of violence among countries have been reported and the same time 157 collaborative agreements have been signed. To achieve effective management of transboundary basins it is essential to have collaborative agreements on the use of waters among the countries that shared them.

\subsection{Ecosystems and Water}

A great number of organisms live in water. Still there is a great number of other plant and animal organisms that are terrestrial, such as humans. Even the bodies of the terrestrial organisms are primarily out of water. Specifically water constitutes $90-95 \%$ of the plants organism while the percentage is lower for animals (on average 68\%). These percentages clearly indicate the necessity of water for the survival of these organisms.

Ecosystem integrity is also threatened by water shortage. Reducing water availability even temporarily is a direct threat to aquatic ecosystem such as lakes, rivers and wetlands but also semi-aquatic ecosystems such as riparian areas. Semi-aquatic ecosystems are the first to be impacted by the increased consumption and degradation of water because of human activities. Consequently wetlands and riparian areas are some of the most threatened ecosystems in the world today. But even the truly terrestrial ecosystems are directly dependent on water. Long periods of droughts can have significant negative impacts on them.

\subsection{Climate Change}

The phenomenon of climate change has been accepted by most of the world's scientific community. The importance of confronting climate change has also been recognized worldwide. The serious consequences of climate change led to Copenhagen Climate Change Conference (COP15) in 2009. This conference was under the United Nations' Climate Change Convention. The purpose was to develop and sign a comprehensive, ambitious and fair International Climate Change deal among the countries of the United Nations.

Most climate change models forecast that the planet's temperature will increase by $2-3^{\circ} \mathrm{C}$ [13]. This increase in temperatures will have immediate impacts on the freshwater resources in two different ways. First of all human water needs will increase because of the higher temperatures year around (e.g. more water consumption because of more human transpiration, hotter summer means higher needs to cool down houses, offices etc.) [14]. In addition, the increased temperatures of the planet will cause changes to the hydrologic circle, worldwide, regionally and locally. Specifically, higher temperatures translate into more energy that will lead to a faster completion of the hydrologic circle. This means more intense and shorter duration meteorological phenomena such as intense rainfalls that will lead to more frequent and larger flood events and afterwards long periods without rainfall that will result in periods of water shortage that if prolonged will lead to droughts. Extensively long periods of drought will lead the desertification of many vegetated regions of our planet.

\subsection{Water Scarcity}

The unequal distribution of water on the planet, the exponential increase of the world population of planet, the increase in daily personal water consumption, the multiple uses of water and the increase levels of water pollution have led to water scarcity being one of the most serious problems of our planet. Climate change impacts will only intensify this problem [15]. The quantities of water on the planet in liquid form will increase because seawater levels will increase due to climate change but the accessibility to drinkable water will decrease because of the increased drought periods. Drinkable water will be more limited to billions of people that will lead health and safety problems. 
Scientists believe that one and half billion people in Asia, in Africa and in Latin America will face mental problems and stress because of lack of drinkable water [15]. In the Western United America there is a high possibility of the Colorado River drying by 2060 an event that would have serious repercussions to the millions of people the river supplies water to (e.g. the metropolitan areas of Las Vegas, Phoenix and Tucson) [15]. Finally, the expected reduction of drinkable waters will heavily affect transboundary basin agreements related to water. Many believe that many countries will want to alter these agreements based on the new hydrologic conditions and this will cause hostilities among neighboring countries that share water resources [10]. This could be a major threat to world peace and safety.

\section{Freshwater Resources of Greece}

Greece is a relatively small country in area. Despite occupying a small area, its precipitation and water resources have a distinct unequal distribution. There are regions in Greece that have precipitation that exceed the $1100 \mathrm{~mm}$ (mountain range of Pindos) while other regions have less than $400 \mathrm{~mm}$ (islands of Cyclades and Crete). To accentuate the problem of water resources the population of Greece is also unequally distributed. The largest percentage of the population lives in the flat and coastal parts and only a small percentage in the mountainous regions. In contrast the mountainous regions have usually significantly more freshwater resources than the flat areas of Greece.

In Greece the majority of water is consumed by agricultural uses $(86 \%)$ followed by urban uses $(11 \%)$ while industry (2\%) and energy (1\%) consuming significantly smaller quantities [16]. Approximately 1,594,000 hectares are irrigated in Greece [17]. These usage percentages change significantly among the various water districts in Greece (Table 1). As an example the Water District of Attica has the largest percentage of urban water consumption $(37.1 \%)$ but a very small percentage for agricultural uses $(1.8 \%)$ while the Water District of Thessaly has the largest percentage of agricultural water consumption $(25.1 \%)$. This shows that the various water districts of the country will face different problems regarding water resources and will need to develop different plans and take different measures to effectively manage them.

In addition, Greece is in the Mediterranean Basin and presents, as most countries of this region, certain peculiarities in its climate. The climate is characterized as Mediterranean, with rainy but not very cold winters, relatively hot and dry summers with many sunny days throughout the year. Usually April till October is the dry period (few rainfalls). In July and August the rainfalls are minimal and these are the periods that severe water shortage can occur that could lead to droughts.

Climate change will have additional impacts on the country once the temperate Mediterranean climate becomes hotter and drier. Temperatures based on climate models are forecasted to increase by 1 to $2^{\circ} \mathrm{C}$ in Greece [13]. The forecasts for rainfall are not as straightforward as temperatures but most forecast important reduction in rainfalls, specifically during the summer months in the regions of Eastern and Southern Greece, particularly in Attica, Thessaly, Thessaloniki and Eastern Peloponnese, regions that already face water scarcity problems.
Table 1. Agricultural and urban consumption for the 14 Water Districts of Greece [16].

\begin{tabular}{lcc}
\hline Water District & $\begin{array}{c}\text { Urban } \\
(\mathbf{\%})\end{array}$ & $\begin{array}{c}\text { Agricultural } \\
(\mathbf{\%})\end{array}$ \\
\hline Western Peloponnese & 3.0 & 3.3 \\
Northern Peloponnese & 4.8 & 6.4 \\
Eastern Peloponnese & 2.2 & 3.2 \\
Western Central Greece & 2.8 & 6.0 \\
Ipiros & 5.5 & 6.0 \\
Attica & 37.1 & 1.8 \\
Eastern Central Greece & 5.4 & 12.5 \\
Thessaly & 6.9 & 25.1 \\
Western Macedonia & 5.1 & 5.9 \\
Central Macedonia & 10.5 & 10.5 \\
Eastern Macedonia & 3.0 & 6.2 \\
Thrace & 3.5 & 6.7 \\
Crete & 5.4 & 5.2 \\
Aegean Islands & 4.8 & 1.4 \\
TOTAL & $\mathbf{1 0 0 . 0}$ & $\mathbf{1 0 0 . 0}$ \\
\hline
\end{tabular}

Every summer, on the islands of Greece but also in other regions that host many tourists, "civil wars" occur between neighboring municipalities and prefectures over the available drinkable water. The phenomenon of shortage of water quantities are more intense in the summer times because of the hot and dry climate but also because of the large number of tourists that visits these regions. During the summer period, the population of these regions can triple or quadruple compared to the population of the winter period.

Another negative fact regarding water resources is that Greece has a very large consumption of water per individual. While the worldwide the mean is 1,243 cubic meters per individual per year, in Greece the mean is 2,389 cubic meters per individual per year [18]. The citizens of the United States have the largest consumption worldwide with 2,480 cubic meters per individual per year while the countries of Southern Europe (Greece, Italy and Spain) follow with 2.300-2.400 cubic meters per individual per year. One of the main reasons for the large consumption of water in these countries is the large consumption of quantities of meat.

Finally $25 \%$ of the terrestrial freshwater resources of Greece originate from neighboring countries [19]. This means that for the effective management of these water resources serious consideration should be given to the European Legislation but also to any other International legislation related to transboundaty waters, in addition to the national legislation. Examples of transboundary terrestrial water bodies of Greece are the rivers of Aoos/Vjosë, Axios/Vardar, Strymonas/Struma, Nestos/Mesta and Ebros/Maritsa as well as the lakes of Doirani, Prespa and Little Prespa.

\section{Recommendations for Sustainable Management}

Greece is in the Mediterranean region, a region with water scarcity frequent occurring because of its climate. In addition, the water resources of Greece are getting drained rapidly because its citizens have one of the largest personal daily water consumption worldwide. With future climate change impacts potentially decreasing water resources availability, it is essential for the sustainability of the country's water resources to develop and implement innovative and environmentally friendly management plans 
that will ensure the future sustainability of this resource in Greece.

To confront any problem, the first step is to recognize the problem. In this case it is essential to understand and recognize that the fresh water resources of Greece are limited and that to be able to face future freshwater related problems, such as water scarcity, it is absolutely necessary to develop holistic long-term management plans. Today in Greece while most recognize that the water resources of the country are limited, very few truly realize that it is limited because everyday water runs from their tap. To become sensitive and concerned for freshwater resource matters, citizens need to be aware and realize the problem. Only when the majority of the citizens' start requesting and demanding from the government to implement sustainable management plans on freshwater resources will the government respond and implement these management plans. The main methods to increase citizens awareness is education. The first initiative for citizens education should include pamphlets, kiosks and television advertisements, means that utilize mass media (e.g. television, newspapers). In addition, education should start with students. These education efforts should start from elementary, middle and high schools and continue at the University level. This would enssure that the future generations of Greeks are more sensitive and aware to freshwater resource problems.

Another important element for sustainable management is the collection of data on the freshwater resources of country. The data should be reliable, collected systematically and for long periods of time. Freshwater resource data can change considerably from year to year depending on the climate conditions of the year. The collection of such datasets for each basin of each European Union country is part of the requirements of the Water Framework Directive. Another big issue with the freshwater resources data is that while in many cases the data do exist they belong to different government services. In Greece the collaboration among the various government services or organizations is limited and difficult because of the bureaucratic restrains. To achieve sustainable freshwater management a key component will be enhanced and comprehensive collaboration among the government services, institutions, organizations, research institutions, Universities and Technological Educational Institutions (TEI) that are related to freshwater resources.

The creation of this reliable and long-term database on the freshwater resource of Greece will provide the necessary information to estimate the water budget for the basins of the country. In addition to the current water budget, models should be used to forecast the future water budgets. For the future water budgets climate change impacts need to be taken into consideration. Once the water budget is estimated this will provide the necessary information to develop the best suitable management plans. These plans should be developed on a watershed or a basin scale. A watershed or basin is the area of land where all of the water that drains off of it goes into the same place. This water originates from the precipitation events that fall within the boundaries of the watershed or basin. From an environmental standpoint the watershed or basin is the best unit to manage water resources because it provides the natural boundaries of water flow. The main problem for the adoption of the watershed or basin unit is that their boundaries do not follow the political borders that humans have created. This will cause many administrative issues that need to be resolved. Another critical factor that needs to be considered when developing management plans is that they need to correspond to the problems of the specific basin. Each basin is unique with its own characteristics and problems. Every management plan needs to take into account all the factors that impact freshwater resources, such as environmental, social and political. Finally, these management plans will become acceptable by the public only when they are clearly written, the process they are developed by is transparent and all the stakeholders have participated in their development. If all interested stakeholders (or the largest percentage of them) do not agree with the management plans it will be very difficult or even impossible to implement them.

The potential impacts of climate change have led to many states in the USA to increase their efforts in drought and flood monitoring. Specifically the United States Drought Monitor (USDM) (see http://www.climas.arizona.edu/swclimate/drought-monitoring) provides drought assessments for the entire country. The USDM provides weekly reports on the certain climatic characteristics of different region such as precipitation, snow, temperature, impact reports, and expert assessments made by scientists. Based on these reports the percent area of the state or regions affected by drought is estimated and presented in the form of maps. These assessments are broad-scale and produced at the national or regional level. In addition the National Climatic Data Center (NCDC) provides monthly summaries on the drought conditions of different regions of the United States. These reports are very important resources that help local governments, resource managers, and many other groups make effective decisions.

Flood can cause many serious damages including in many cases the loss of life. With climate change potentially increasing the severity and frequency of floods, early warning systems are a priority of most developed countries. Such warning systems have been developed in the USA (see http://www.azwater.gov/AzDWR/SurfaceWater/FloodMitig ationSection.htm), Europe (see http://floods.jrc.ec.europa.eu/) and in Australia (see http://www.bom.gov.au/hydro/flood/). These programs typically include many organizations collaborating in order to forecast potential floods. Typically the mission of these programs is to reduce the loss of lives, property, and water resources by providing appropriate flood information through the development of a regional flood warning system available to the proper authoties local entities and citizens of the region. Potentially such programs on droughts and flood at the national scale can also be developed in Greece with the involvement of the Greek national, regional and local government, national research institutes and Universities and TEI.

In any case the management plans will depend on the needs of each specific basin while also being innovative in order to best exploit the freshwater resources in a sustainable and environmentally-friendly way. These components are essential because it is expected that the consumption of drinkable water will increase while the quantities will remain the same of will decrease because of different causes e.g. pollution. The management plans proposed should also focus on water saving techniques e.g. use of more effective irrigation systems, drip irrigation instead of sprinklers or use crops that require smaller quantities of water. In only $49 \%$ of the irrigated surfaces of Greece utilize water saving equipment [16]. Using this type of equipment can lead to significant water savings. For example gravity irrigation consume $5,000-10,000 \mathrm{~m}^{3}$ per hectare per day while sprinkler irrigation reduces water consumption to 1,500 $5,000 \mathrm{~m}^{3}$ per hectare per day while localized irrigation (drip) 
1,000-3,000 $\mathrm{m}^{3}$ per hectare per day. Another main priority should be reducing river and lake pollution. This can be accomplished with conservation practices in the agricultural regions that could include planting trees, shrubs or multiannual grasses and forbs in the riparian areas, creation of terraces, no-till cropping, avoid over-fertilization and the use of pesticides in agricultural fields. In urban areas the creation of wastewater treatment facilities is a necessity. There should also be serious efforts in promoting the reuse of waste water. In most developed countries a significant percentage (up to $10 \%$ ) of the water used originates from recycled water. This recycled water is typically used for the irrigation of house yards and golf courses.

Finally all countries are reducing public expenditures in the all sectors including the environment. In most government services and organizations while the number of employees has or is being decreased their responsibilities have increased. Because of this reason in many developed countries volunteers are being educated for the conservation and protection of water resources. University extension offices are playing a very active role in the education of these volunteers. These Universities have departments and schools related to freshwater resources. In the USA most states have created the "Master Watershed Stewards program" in which government agencies collaborate with the state's University for the education of volunteers (see http://ag.arizona.edu/watershedsteward/,

http://extension.oregonstate.edu/watershed/watershed-stewards and http://www.usawaterquality.org/themes/watershed/extension /stewards.html). The goal of this program is the creation of voluntary teams that will be active in the watershed or basin they live in. Similar educational programs could be created in Greece between the Greek government and Universities and TEI to train initially simple citizens that will afterwards can become active volunteers.

Overall if brave decisions are not taken and innovative sustainable management plans are not implemented today, the future generations will face serious problems in regard to freshwater resources. The decisions of this generation will determine the future sustainability of the country's water resources.

\section{References}

1. P.H. Gleick, Encyclopedia of Climate and Weather, Oxford University Press, New York, (1996) 817-823.

2. United Nations Development Programme, United Nations Environment Programme, World Bank, World Resources Institute, World Resources 2000-2001: People and Ecosystems: The Fraying Web of Life, World Resources Institute, (2000).

3. Pidwirny M., Global Distribution of Precipitation. Fundamentals of Physical Geography, 2nd Edition 2006. http://www.physicalgeography.net/fundamentals/8g.html

4. Blue Plan, Water Demand Management in the Mediterranean, Progress and Policies. Proceedings of the 3rd Regional Workshop on Water and Sustainable Development in the Mediterranean (2007).

5. P. Ehrlich and A. Ehrlich, The Population Explosion. Simon and Schuster, New York (1990).

6. R. Gallant, The Peopling of the Planet Earth. Macmillian Publishing Company, New York (1990).

7. USEPA (United States Environmental Protection Agency), Report to Congress for the 2002 Reporting Cycle - A Profile. The National Water Quality Inventory, Washington, DC (2007).

8. E.D. Ongley, Control of water pollution from agriculture. Food and Agriculture Organization of the United Nations, Rome (1996).

9. European Union Parliament, Off. J. Eur. Com. 327 (2000) 1.

10. H. Haddadin, Water Pol. 2, 205 (2002).
11. J. Uitto and M. Duda, Geograph. J. 168, (2002) 365.

12. C. Sadoff and D. Greym, Water Policy 4, (2002).

13. R.K. Pachauri and A. Reisinger, A. (ed.), Climate Change 2007: Synthesis Report, Contribution of Working Groups I, II and III to the Fourth Assessment Report of the Intergovernmental Panel on Climate Change, IPCC, Geneva (2007).

14. C.J. Vorosmarty, P. Green, J. Salisbury and R.B. Lammers, Science 289, 284 (2000).

15. M.L. Parry, O.F. Canziani, J.P. Palutikof, P.J. van der Linden and C.E. Hanson (ed.), 2007. Contribution of Working Group II to the Fourth Assessment Report of the Intergovernmental Panel on Climate Change. Cambridge University Press, Cambridge (2007).

16. M.A. Mimikou, Global NEST J. 7, 313 (2005).

17. Blue Plan. Water Demand Management in the Mediterranean, Progress and Policies. MAP Technical Report Series No. 168, Athens, (2008).

18. A.Y. Hoekstra and A. K. Chapagain, 2007. Water Resour. Manage, 21 (2007) 35.

19. Y.A. Mylopoulos and E. G. Kolokytha, Phys. Chem. Earth 33 (2008) 347.

20. Food and Agriculture Organization of the United Nations (FAO), Agriculture: Towards 2015/2030. Global Presepctive Study Unit, Washington, DC (2000). 